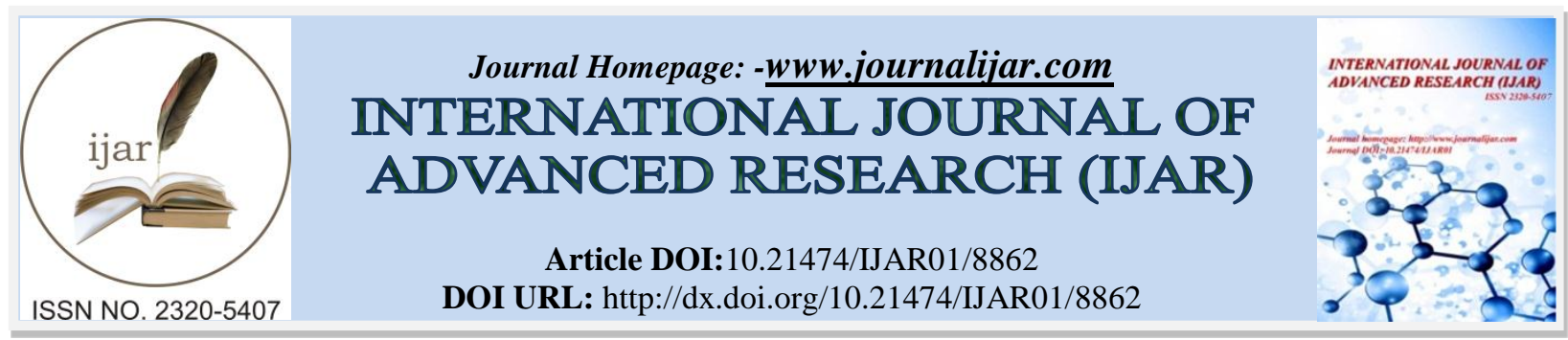

RESEARCH ARTICLE

\title{
AMBIDEXTERITY OF IMMORTAL PLANT IN DENTISTRY.
}

\section{Dr. Abhilash. R. Krishnan ${ }^{1}$, Dr. Sarika. S. Kamal ${ }^{2}$, Dr. Alaka subodh ${ }^{3}$, Dr. Nikhil S Rajan ${ }^{4}$ and Dr. Nissy Elizabeth George 5 .}

1. MDS, Reader, Dept of Oral Medicine and Radiology,Sri Sankara Dental College,Varkala, Trivandrum (Dist).

2. BDS,Lecturer,Dept of Oral Medicine and Radiology,Sri Sankara Dental College,Varkala, Trivandrum (Dist).

3. MDS,Senior Lecturer,Dept of Public health dentistry,Sri Sankara Dental College,Varkala, Trivandrum (Dist).

4. MDS,Reader Dept of Prosthodontics,Sri Sankara Dental College,Varkala, Trivandrum (Dist).

5. MDS,Senior Lecturer,Dept of Prosthodontics,Sri Sankara Dental College, Varkala, Trivandrum (Dist).

\section{Manuscript Info}

\section{Manuscript History}

Received: 10 February 2019

Final Accepted: 12 March 2019

Published: April 2019

Key words:-

Aloe vera gel, Apthous ulcer, Lichen Planus.

\section{Abstract}

Plant of immortality is the term used by Egyptians to describe aloe vera since it can be vital and effloresce even in truancy of soil. Aloe vera is the primeval medicinal plant ever known and the most applied medicinal plant worldwide. Its apposite in dentistry is reviewed below par. Many researchers have gathered interest in regarding the use of this plant as antiseptic, anti inflammatory, antiviral and antifungal. Aloe vera is also non allergic and good in boosting up the immune system. Aloe vera is gaining great popularity in dentistry as it is completely natural and thus reported to have no side effects. This article is steered to concisely review the history of use of aloe vera in medicine, its active ingredients, mechanism of action, clinical uses related to dentistry and its possible corollary.

Copy Right, IJAR, 2019,. All rights reserved.

\section{Introduction:-}

Aloe vera is the oldest medicinal plant ever known and is acclaimed for its medicinal and cosmetic properties. ${ }^{1}$ The name Aloe vera derives from the Arabic word Alloeh meaning shining bitter substance, while vera in Latin means true. ${ }^{2}$ Aloe barbadensis Miller (Aloe vera) is one among the 360 species belonging to the liliaceal family. It develops water-storage tissue in the leaves and survive in dry areas of low or erratic rainfall. So aloe vera is categorized as a perennial succulent xerophytes. Aloe vera has 15 to 30 fleshy leaves up to $0.5 \mathrm{~m}$ long and is 8 to $10 \mathrm{~cm}$ across the base. It has a Saw-like teeth mark along the margins of the leaves. The aloe vera plant has mainly two parts, the parenchyma and pericyclic tubules and they produce substances with completely different compositions and therapeutic properties. The parenchymal tissue configures the inner portion of the aloe leaves and produces the Aloe vera gel (or mucilage) which is a clear, thin, tasteless, jelly-like material which is extracted from the leaf by separating the gel and the inner cellular debris. Second component, the pericyclic tubules consist of specialized cells, which occur just beneath the outer green ring of the leaf and yield an exudate that consists of bitter yellow latex with powerful laxative-like actions. ${ }^{3,4}$ Benefits associated with Aloe vera have been attributed to the polysaccharides contained in the gel of the leaves. Numerous studies on Aloe vera are being done to demonstrate the antiviral, antibacterial, analgesic, anti-inflammatory \& wound healing properties. ${ }^{3}$

Corresponding Author:-Dr. Abhilash. R. Krishnan.

Address:-MDS, Reader, Dept of Oral Medicine and Radiology,Sri Sankara DentalCollege,Varkala, Trivandrum (Dist). 


\section{History}

Aloe Vera had a significant medicinal role for past thousands of years. The dried latex was primarily used by Egyptians, Assyrians, and Mediterranean people. In Egypt, aloe vera was called "the plant of immortality" and was given as an offering at the funerals of pharaohs and used in the baths of Egyptian queens Nefertiti and Cleopatra. Pliny, a Roman scholar, reported that the plant was also used for embalming. Alexander the Great conquered Socotra Island, reportedly at the request of Aristotle, just to obtain aloe vera. In the first century C.E., the Greek physician Dioscorides used aloe vera for mouth infections, sores, wounds and as a purgative. In the10th century, aloe vera was used in England and during the $17^{\text {th }}$ century, records show that the East India Company frequently purchased aloe vera from the king of Socotra. Today, Egyptians still hang an aloe vera plant over the door of a new house to provide a long and fruitful life for its occupants. In India the whole leaves, exudate, and fresh gel of aloe vera are used as a cathartic, stomachic, emmenagogue, and antihelmintic. Its used as a common household remedy in China, Mexico, and the West Indies. Until the 1930s in the U.S., the primary commercial use of aloe vera was the dried latex as a laxative. ${ }^{5}$

The Components of Aloe vera. ${ }^{4,6}$

1. Lignins: which are seen in the pulp of the leaf gel, they have the capability to penetrate tissue and carry elements with it.

2. Saponins: they are antiseptic and promote cleansing

3. Anthraquinones: they have an analgesic action and has antibacterial and antiviral properties

4. Minerals: they interact with the vitamins, co-enzymes and proteolytic enzymes.

5. Vitamins: Essential for maintenance of our health and function well as catalyzing agents.

6. Mono and Polysaccharides: Mainly carbohydrates.

7. Amino Acids:act as a building blocks for repair and regeneration of traumatized tissue.

Mechanism of Action:

Anti-Inflammatory Effects:

Anti-inflammatory action is by inhibiting the cyclooxygenase pathway and reduces prostaglandin E2. Aloe vera contains compound like bradykinase which will break down the bradykinin, which is a pain inducing inflammatory substance. Anti-inflammatory compound called C-glucosyl chromone was also isolated from aloe vera gel extracts. 7

\section{Anti microbial Property:}

Studies conducted by Sema Agaoglu, Alemdar Suleyman on investigation of in vitro antimicrobial activity of Aloe vera juice demonstrated the action of aloe vera inner gel against both Gram-positive and Gram-negative bacteria. Streptococcus pyogens and Streptococcus faecalis are two microorganisms that have been inhibited by Aloe vera gel. It was bactericidal against Pseudomonas aeruginosa. ${ }^{8}$ Sen BH and co researchers in 1999 reported the antifungal action of aloe vera gel preparation by inhibiting the growth of Candida albicans. ${ }^{9}$

Aloe emodin and anthraquinones in Aloe vera contribute to its antiviral efficacy. Aloe vera is virucidal to Herpes simplex virus type 1 and type 2, Varicella zoster virus, pseudo rabies virus and influenza virus according to the research of Thomson. During the course of these studies it was found that the virucidal activity was due to the anthraquinones extracted from the inner leaf of Aloe vera and the roots, bark, or leaves of a number of other anthraquinone-containing plants. ${ }^{10}$

\section{Immunomodulating Effects:}

Aloe vera, contains rhodium and iridium (trace minerals) which is one of the polysaccharides which dramatically increases the white blood cells or macrophages and $\mathrm{T}$ cells. Thus, immunomodulating effects occur via activation of macrophage cells to generate nitric oxide, secrete cytokines (e.g., tumor necrosis factor, interleukin-1, interleukin-6, and interferon- $\gamma$ ), and present cell surface markers. It helps enlarge the thymus gland in size by $40 \%$. The thymus is what produces the $\mathrm{T}$ cells of the immune system. ${ }^{11}$

\section{Antioxidant Property:}

Glutathione peroxide activity, superoxide dismutase enzymes and a phenolic antioxidant in Aloe vera gel may be responsible for these antioxidant effects. Apart from these, it also contains A, C and E vitamins. ${ }^{12}$ 


\section{Antitumor Effect:}

The two fractions from Aloes that are claimed to have anticancer effects include glycoproteins (lectins) and polysaccharides. The antitumor activity of Aloe vera gel in terms of reduced tumor burden, tumor shrinkage, tumor necrosis, and prolonged survival rates was reported in many studies. Aloe gel induces glutathione S-transferase which inhibit tumor-promoting effect of phorbol myristic acetate that helps in cancer chemoprevention. Indirect action on antitumor activity is stimulation of the immune response. ${ }^{13}$

\section{Dental Applications of aloe vera}

Aloe vera has numerous applications in dentistry. They are used in the management of immunological diseases such as oral lichen planus, pemphigus, herpetic lesions, recurrent apthous stomatitis, angular cheilitis, post periodontal surgery care, traumatic injuries, chemical burns, application at extraction sockets, as a denture adhesive, can also be used around dental implants to control inflammation caused by bacterial contamination. ${ }^{14-17}$

Anticariogenic Activity:

Strong bactericidal activity of Aloe vera in both cariogenic and periodontic pathogens was demonstrated by Mohammad Mehdi Fani. Aloe vera in undiluted form showed significant growth inhibition zones against all of the oral bacteria tested. In an experiment done, the mean MIC values for Aloe vera gel measured by the micro dilution method against clinical isolates of S.mutans, was $12.5 \mu \mathrm{g} / \mathrm{ml} .^{18}$

\section{Aloe vera in periodontal disease:}

Aloe vera when used at full strength reduced accumulated plaque significantly. ${ }^{17}$ It is extremely helpful in the treatment of gingivitis and periodontitis. Aloe Vera greatly reduces the instances of gingival bleeding due to its soothing \& healing properties, reduces swelling and soft tissue edema. Aloe vera mouthwash can be an effective antiplaque agent and with appropriate refinements in taste and shelf life can be an affordable herbal substitute for chlorhexidine. ${ }^{15}$ Direct Application directly to the periodontal surgical site promotes healing.

\section{Apthous Stomatitis:}

Topical application of aloe vera oral gel is found to reduce pain score, wound size and healing period in patients with apthous stomatitis. ${ }^{19}$. It has been reported that acemannan hydrogel, a component in aloe vera accelerates the healing of aphthous ulcers and reduces the pain associated with them. ${ }^{17}$ Acemannan, has been used for the treatment of oral apthous ulceration in patients who do not prefer steroid medication. US Food and Drug Administration has also found a derivative of Aloe vera an effective treatment alternative in treating oral ulcers ${ }^{19}$

\section{Oral lichen planus:}

1. Topical application of Aloe Vera, three times a day improves the pain score and severity of oral lichen planus. ${ }^{20}$

2. Advantage of aloe vera over steroid therapy is its minimal adverse reactions and better clinical results. ${ }^{19}$

\section{Alveolar Osteitis:}

SaliCept patch, special bandages containing freeze-dried Acemannan Hydrogel are commercially available for intraoral use after tooth extraction. ${ }^{15}$ After extraction, gauze saturated with Aloe vera when placed in socket and asked by the patient to bite on it, has shown improved healing \& formation of blood clot. ${ }^{16}$

\section{Denture Adhesive:}

Acemannan, a complex mannose carbohydrate, which is one of the main ingredients of the aloe vera gel was found to have good adhesive properties. ${ }^{19}$ The acemannan based new denture adhesive formulations were evaluated for $\mathrm{pH}$ changes, cytotoxicity to human gingival fibroblasts and improve adhesive strength in dry and wet conditions. In an experiment carried out, it was concluded that acemannan denture adhesive formulation with an initial $\mathrm{pH}$ value of 6.0 was an effective herbal substitute for traditional denture adhesives. ${ }^{15}$

\footnotetext{
Aloe Vera in Endodontics:

Aloe vera has numerous roles in endodontics ranging from sedative dressing to file lubrication during biomechanical preparation, root canal disinfection and decontaminating gutta-percha cones. Aloe vera contains anthraquinone, an antibacterial agent has proved to be effective against E. Faecalis which is frequently isolated from failed endo treated canals. Aloe vera gel can be used effectively in decontaminating GP cones. Aloe vera has proved to be a good obturative material for primary teeth. ${ }^{17,19}$
} 


\section{Implant dentistry:}

Aloe vera gel applied topically around dental implants minimized the degree of inflammation. ${ }^{16}$

\section{Aloe vera as a tooth gel:}

The aloe vera tooth gel has no added fluoride content but still exerts almost an equal amount of antimicrobial activity. ${ }^{21}$ It is less acrid on teeth as it does not have the abrasive elements and hence is a better alternative for people with sensitive teeth or gums. ${ }^{16}$ Studies have reported that aloe vera tooth gel and the aloe vera containing toothpastes were equally effective against Candida albicans, Streptococcus mutans, Lactobacillus acidophilus, Enterococcus faecalis, Prevotella intermedia and Peptostreptococcus anaerobius. It also shows enhanced antibacterial effect against S. Mitis. ${ }^{22}$

\section{Aloe vera as a mouthwash:}

Aloe vera mouthwash may not only prevent radiation-induced mucositis by its wound healing and anti-inflammatory mechanism, but also may reduce oral candidiasis of patients undergoing head and neck radiotherapy due to its antifungal and immunomodulatory properties. ${ }^{19}$ It is recommended that 1-3 tablespoon of aloe vera juice be used as a mouthwash, then swallowed, three time daily. ${ }^{16}$

\section{Contraindications}

Aloe vera is not advisable in patients who are allergic to plants in the Liliaceae family. ${ }^{16}$ Contact dermatitis and hypersensitivity reactions are reported in few cases after topical applications of aloe vera. ${ }^{19}$ Aloe should not be used during pregnancy or lactation except under medical supervision. Aloe vera should not be given orally to children under 10 years of age. In diabetic patients, increased hypoglycemia might be seen in conjunction with oral antidiabetics or insulin. Aloe vera gel for systemic application is not recommended in combination with antidiabetic, diuretic, or laxative drugs; sevoflurane; or digoxin. ${ }^{19}$ Application of aloe vera to skin may increase the absorption of steroid creams such as hydrocortisone. Due to the potassium lowering effect, it reduces the effectiveness and might increase the adverse effects of digoxin and digitoxin. The combination of aloe vera and furosemide increases the risk of potassium depletion. It decreases the blood sugar levels and, thus, may interact with oral hypoglycaemic drugs and insulin. ${ }^{16}$

\section{Adverse effects:}

Local application of aloe vera has developed redness, burning, stinging sensation and rarely generalized dermatitis in sensitive individuals hence it should be applied to small areas to check for possible allergic reaction. ${ }^{16}$ Systemic administration has caused abdominal cramps, diarrhea, red urine, hepatitis, dependency or worsening of constipation. The prolonged use can increase the risk of colorectal cancer. ${ }^{16}$

\section{Conclusion:-}

Ambidexterity of Aloe vera could make it a valuable medicament in the discipline of dentistry. The usage of aloe vera in dentistry is minimal due to lack of commercially available product for dental use. Moreover, the efficacy of aloe vera in various conditions needs to be evaluated. Other factors of concern are the affirmation of aloe vera products and the potential long term adverse effects.

\section{References:-}

1. Rajeswari $\mathrm{R}$ et al, Aloe vera: The Miracle Plant Its Medicinal and Traditional Uses in India, Journal of Pharmacognosy and Phytochemistry.2012; 1(4) :118-24

2. Botelho A, NAP Nogueira, GM Bastos. Antimicrobial activity of the essential oil from Lippia sidoides, carvacrol and thymol against oral pathogens. Brazilian Journal of Medical and Biological Research. 40(3), 349356.

3. Richa Wadhawan, Siraj Daa Khan, Gaurav Sabreena. Aloe Vera: A boon in dentistry. Journal of pharmacy review and research2014; 4(3) 147-151.

4. Heggers JP, Kucukcelebi AD. Beneficial effect of Aloe on wound healing in an excisional wound model. Journal of Alternative and Complementary Medicine, 2(2), 1996, 271-277.

5. Crosswhite, F. and Crosswhite, C. 1984. Aloe vera, Plant Symbolism and the Threshing Floor: Light, Life and Good in Our Heritage. Desert Plants. 43-50

6. Davis RH, Leitner MG, Russo JM and Byrne ME. Anti-inflammatory activity of Aloe vera against a spectrum of irritants. Journal of the American Podiatric Medical Association, 79(6), 1989, 263-276. 
7. Hutter JA, Salman M, Stavinoha WB. Anti-inflammatory C-glucosyl chromone from Aloe barbadensis. Journal of Natural Products, 1996, 59(5), 541-543.

8. Sema Agaoglu, Alemdar Suleyman J. Investigation of in vitro antimicrobial activity of Aloe vera juice. J Anim Vet Adv, 8(1), 2009, 99-102.

9. Sen BH, AKdeniz BG, Denizci AA. The effect of ethylenediamine- tetraecetic acid on C Albicans OOOE, 90, 2000, 651-5.

10. Sydiskis RJ, Owen DG, Lohr J, Rosler KH and Blomster RN. Inactivation of enveloped viruses by anthraquinones extracted from plants. Antimicrobial Agents and Chemotherapy, 35(12)fc, 1991, 2463-2466.

11. Im SA, Oh ST, Song S. Identification of optimal molecular size of modified Aloe polysaccharides with maximum immunomodulatory activity. International Immunopharmacology, 5, 2005, 271-279.

12. Khan MA, Tania M, Zhang D and Chen H. Antioxidant enzymes and cancer. Chinese Journal of Cancer Research, 22(2), 2010, 87-92.

13. Yagi A, Egusa T, Arase M, Tanabe M, Tsuji H. Isolation and characterization of the glycoprotein fraction with a proliferation-promoting activity on human and hamster cells in vitro from Aloe vera gel. Planta Med, 63, 1997, 18-21.

14. Sundarkar $\mathrm{P}$ et al, Use of Aloe Vera in dentistry, Journal of Indian Academy of Oral Medicine and Radiology.2011; 23(3): S389-91

15. Sajjad A, Aloe vera: An Ancient Herb for Modern Dentistry-A Literature Review, Journal of Dental Surgery, 2014: 1-6

16. Meena $\mathrm{M}$ et al, Aloe vera - An Update for Dentistry, Journal of dentofacial sciences. 2013; 2(4): 1-4

17. Tulsi Subramaniam, Arun Subramaniam, Asha Chowdhery, Sreeja Das, Mishali Gill Versatility of Aloe Vera in Dentistry- A review. Journal of Dental and Medical Sciences.2014;13(10): 98-102

18. Rathi S, Role of aloe vera in dental practice- a review, The Pharma Research, 2013; 10(1): 1-5

19. Tayal E et al, Current Perspectives on Use of Aloe vera in Dentistry, European Journal of Medicinal Plants, 2014; 4(12): 1408-19

20. Salazar-Sa 'nchez et al, Efficacy of topical Aloe vera in patients with oral lichen planus: a randomized doubleblind study, J Oral Pathol Med, 2010; 39: 735-40

21. George D et al, Comparative evaluation of the antimicrobial efficacy of aloe vera tooth gel and two popular commercial toothpastes: An in vitro study, General Dentistry, 2009: 238-41

22. Sambhav J, Rai R, Aloe-Vera: A Boon In Management Of Dental Disease, Int. J. Pharm. Res. Sci., 2014; 2(1): $18-24$. 